CONVENIENT SYNTHESIS OF $\beta, \gamma$-UNSATURATED $\gamma$-DITHIOLACTONES FROM ALLENYLSILVER(I) COMPOUNDS

H. Westmijze, K. Ruitenberg, J. Meijer and P. Vermeer.

(Department of Organic Chemistry of the University, Croesestraat 79, 3522 AD Utrecht, The Netherlands)

Abstract Allenylsilver(I) compounds react with carbon disulfide to silver(I) 3-alkynedithioates; $\beta, \gamma$-unsaturated $\gamma$-dithiolactones are formed by spontaneous cyclisation of these dithioates.

Recent $1 y^{1}$ we reported on an interesting 1,4-addition reaction of alkylsilver(I) reagents with conjugated enynes. We showed that protolysis of the resulting adducts afforded allenes in excellent yields $(70-90 \%) .^{1}$

To investigate the synthetic applicability of these adducts further, we have allowed them to react with several electrophiles. The present paper describes our preliminary results concerning their behaviour towards carbon disulfide. The observed reaction with carbon disulfide is namely yery remarkable as it leads to silver(I) salts of $\beta, \gamma$-unsaturated $\gamma$-dithiolactones. ${ }^{2}$

Thus treatment of adducts $\underline{1}(0.03 \mathrm{~mol}$, eq 1$)$, obtained from RAg. $2 \mathrm{LiBr}$ and 2-methy1-1-buten-3yne ( $\mathrm{cf}^{1}$ ), with one equivalent of carbon disulfide in a mixture of tetrahydrofuran (THF, $150 \mathrm{~m} 1$ ) and hexamethylphosphoric triamide (HMPT, $15 \mathrm{ml}$ ) for $1 \mathrm{~h}$ at $-50^{\circ} \mathrm{C}$ followed by stirring of the reaction mixture for $1 \mathrm{~h}$ at $+25^{\circ} \mathrm{C}$ furnished the $\beta, \gamma$-unsaturated $\gamma$-dithiolactones 4 in a high yield $(80-95 \%)$ upon protolysis $(E=H)$ or deuteriolysis $(E=D)$. Based on the evidence given below, the reaction is thought to proceed via the silver(I) salts $\underline{2}$ and $\underline{3}$ :

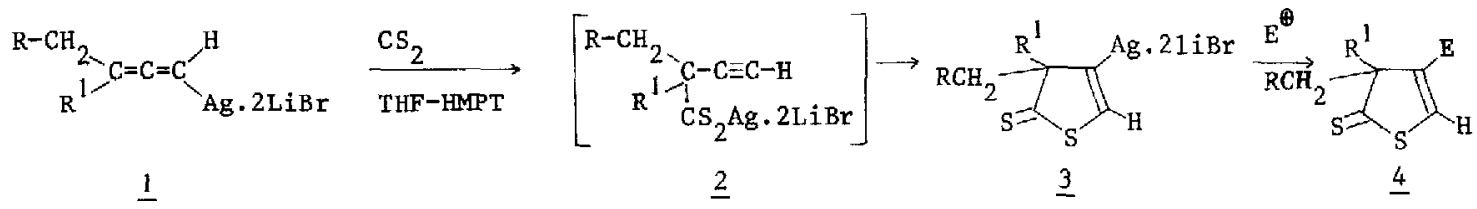

$\mathrm{R}^{1}=\mathrm{Me} ; \mathrm{E}=\mathrm{H}(\mathrm{R}=\mathrm{Bu}, \mathrm{i}-\mathrm{Pr}, t-\mathrm{Bu})$ or $\mathrm{D}(\mathrm{R}=t-\mathrm{Bu})$

According to ${ }^{1} H-M M R$ and GLC (SE 33 column) analysis dithiolactones 4 were reasonably pure $\geqslant 95 \%$ ). The ${ }^{1} \mathrm{H}$-NMR spectra of all compounds $\underline{4}\left(\mathrm{CDCl}_{3}\right.$, TMS) showed absorptions in the range $\delta 6.62-6.67$ (vinylic proton on $C_{\gamma}$ ); when $E$ was hydrogen, an additional absorption in the region $\$ 6.20-6.42$ was present (vinylic proton on $\mathrm{C}_{\beta}$ ). 
The proposed ring closure of $\underline{2}$ into $\underline{3}$ is based on ${ }^{1} \mathrm{H}-\mathrm{MMR}$ evidence. When namely a ${ }^{1} \mathrm{H}-\mathrm{MMR}$ spectrum was recorded from a THF-HMPT solution containing the adduct of 1 ( $\left.R=i-P r, R^{1}=M e\right)$ with carbon disulfide, a sharp singlet was found at $\delta 5.85$ (vinylic proton; $\delta \mathrm{TMS}=0 \mathrm{ppm}$ ) which integrated in a ratio 1:6 with the isopropyl group. In the spectrum no other isopropyl groups were present. Apparently, the 3-alkynedithioate $\underline{2}$ was not stable under the conditions of the reaction and had completely cyclised into 3 . This explains why it was not possible to form methyl 3-a1kynedithioates by treating the adduct obtained from 1 and carbon disulfide with methyl iodide. ${ }^{3}$

An alternative route to dithiolactones 4 was found in the reaction of allenyllithium compounds (5. eq 2; studied for $R=i-P r$ and $\left.R^{1}=M e\right)^{4}$ with carbon disulfide. Addition of one mol equiv. of $\mathrm{AgBr} .2 \mathrm{LiBr}$ to the adduct of $\underline{5}$ with carbon disulfide and subsequent protolysis furnished dithiolactone 4 ( $\left.R=i-\mathrm{Pr}, \mathrm{R}^{1}=\mathrm{Me}\right)$ in $80 \%$ yield. In this case the 3 -alkynedithioate (6, eq 2$)$ was stable. This follows from its smooth methylation into dithioester $\underline{7}$ (yield: 75\%; IR (NaC1): $3295 \mathrm{~cm}^{-1}$ $(\mathrm{H}-\mathrm{C} \equiv) ;{ }_{\mathrm{H}-\mathrm{MMR}}\left(10 \% \mathrm{v} / \mathrm{v}\right.$ solution in $\left.\mathrm{C}_{6} \mathrm{D}_{6}, \delta \mathrm{TMS}=0 \mathrm{pPm}\right): \delta 2.39(\mathrm{~s}, \mathrm{H}-\mathrm{C} \equiv) ; \delta 2.22(\mathrm{~s}, \mathrm{~s}-\mathrm{Me}) ; \delta 1.64$ $(s, \mathrm{Me}) ; \delta 0.98,80.83$ (2xd, isopropy1).

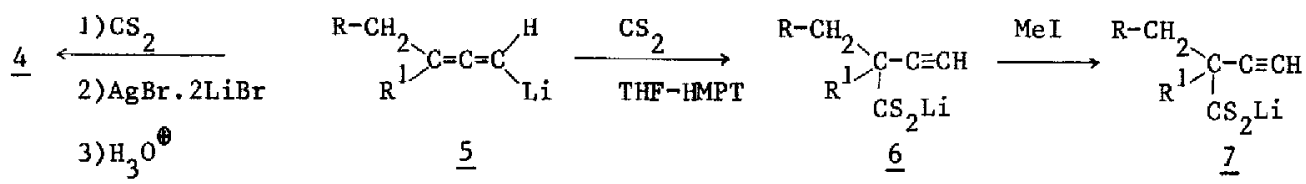

In view of the formation of tarry products from 1 in which $R^{3}$ is hydrogen, our dithiolactone synthesis seems to be restricted to dithiolactones which bear two substituents on $\mathrm{C}_{\gamma}$. Currently, we are investigating the scope of this interesting reaction further.

Acknowledgement This investigation was supported by the Netherlands Foundation of Chemical Research (SON) with financial aid from the Netherlands Organization for the Advancement of Pure Research (ZWO).

\section{Refercnces and notes}

1. H. Westmijze, H. Kleijn and P. Vermeer, J. Organometal. Chem. 172, 377 (1979).

2. This type of dithiolactones is scarcely known in the literature. One related example, viz.<smiles>CC(C)C=C1C=CC=[SH]1</smiles>
has been published by Ya.L. Gol'dfarb and M.A. Kalik, Bull. Acad. Sci. USSR $1973,2017$.

3. Methylation of $\underline{3}$ didn't occur either.

4. D. Michelot and G. Linstrume1le, Tetrahedron Lett. 1976, 275.

5. The fact that the dithiolactone obtained from $\underline{5}$ was identical to the one formed from $\underline{1}$ excludes a $\alpha, \beta$-unsaturated $\gamma$-dithiolactone structure for our compounds $\underline{4}$ viz., Such dithiolactones would arise by ring closure of $\mathrm{RCH}_{2} \mathrm{CR}^{1}=\mathrm{C}=\mathrm{CHCS}_{2} \mathrm{Ag} \cdot 2 \mathrm{LiBr}$.

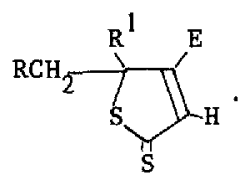

